\title{
ANALISIS ASPEK TEKNIS OPERASIONAL PENGELOLAAN SAMPAH DI RSUD ADE MOEHAMMAD DJOEN KOTA SINTANG
}

\author{
Adidtya Resnu Pradipta, Dian Rahayu Jati,S.T,M.Si, Isna Apriani, S.T, M.Si \\ Program Studi Teknik Lingkungan, Fakultas Teknik, Universitas Tanjungpura, Pontianak \\ Email : resnu1990@gmail.com
}

\begin{abstract}
ABSTRAK
Permasalahan yang timbul di RSUD Ade M. Djoen Sintang yaitu ketersediaan sarana dan prasarana yang masih kurang dan penanganan pengelolaan sampah yang masih belum berjalan dengan baik. Terkendala pada operasional pengolahan sampah mengakibatkan penumpukan sampah medis maupun nonmedis di RSUD Ade M. Djoen Sintang, yang seharusnya dikelola dan di lakukan pengolahan setiap harinya. Tujuan penelitian ini adalah untuk identifikasi dan menganalisa pengelolaan persampahan terutama aspek teknis operasional, memberikan rekomendasi terhadap pengelolaan persampahan. Pengambilan data primer dilakukan dengan cara sampling timbulan dan menentukan komposisi sampah. Sampling dilakukan dengan metode SNI 19-3964-1994. Ketersediaan wadah yang ada sebanyak 25 wadah sampah medis dan 25 wadah sampah nonmedis, total wadah sebanyak 50 wadah sampah. Dengan kondisi demikian perlu dilakukan penambahan wadah sampah dikarenakan wadah yang tersedia masih belum cukup untuk menampung sampah yang dihasilkan dari aktifitas kesehariannya di rumah sakit tersebut. Penambahan wadah sesuai perhitungan selama pengamatan berlangsung dengan kondisi tempat tidur pasien tidak penuh diperlukan sebanyak 13 wadah sampah medis dan 13 wadah sampah nonmedis. Dibandingkan dengan standar WHO, rata-rata rumah sakit menghasilkan sampah sebanyak 3,2 kg/bed/hari, dengan menggunakan kapasitas wadah medis dan nonmedis sebesar 60 liter, rumah sakit Ade M. Djoen memerlukan wadah sampah sebanyak 176 wadah sampah medis dan 176 wadah sampah nonmedis dalam kondisi tempat tidur pasien terisi penuh. Untuk pengangkutan sampah nonmedis menggunakan troli dengan kapasitas 1,5 $\mathrm{m}^{3}$, sedangkan sampah medis diangkut secara manual. Rekomendasi diantaranya menambah fasilitas pendukung diantaranya troli pengangkut sampah, wadah sampah dan memberi penamaan/label pada masing-masing wadah sampah, memperhatikan pelaksanaan pengelolaan sampah dan memberi pelatihan dan pengetahuan lebih tentang pengelolaan sampah rumah sakit sesuai regulasi yang berkaitan diantaranya Permenkes R.I Nomor 1204/Menkes/SK/X/2004 tentang persyaratan kesehatan lingkungan rumah sakit, Peraturan Pemerintah R.I no.18 Tahun 1999 tentang pengelolaan limbah B3.
\end{abstract}

Kata kunci : Pengelolaan sampah rumah sakit, Teknis operasional pengelolaan sampah, Sampah medis dan nonmedis.

\begin{abstract}
Problem which emerge at Ade M. Djoen Sintang Hospital are availability of tools and infrastructure still less and handling preparation of rubbish still not well. Obtacle to operational preparation of rubbish which result accumulation medic and nonmedic rubbish at there, who must managed and done it every day. Purpose of this observation are to identify and analyze preparation of rubbish especially technical operational aspect, give recommendation to preparation of it and interpretation primary data to done by search sampling and establish composition of it. Sampling had done by SNI metode 19-3964-1994. Availability container which the existing as many as 25 container of medic rubbish and same for nonmedic rubbish, completely of all as many as 50 container of rubbish. With the condition need to done adding container because it just available still not enough to recieve rubbish who producing it from daily activity at the hospital. Adding container appropriate calculated during continue observation with the condition patient's bed not full which 13 container of medic rubbish and same for nonmedic rubbish. Comparison with WHO standart, average of Hospital producing rubbish as many as 3,2 $\mathrm{kg} / \mathrm{bed} /$ day, by means of using container medic and nonmedic rubbish as many as 60 liter, it require container rubbish in condition patient's bed full. For transport nonmedic rubbish require
\end{abstract}


by troly in capacity $1,5 \mathrm{~m}^{3}$, whereas medic rubbish require by manual. This recommendation are adding proponent fasility like trolly rubbish tansport, container, giving label to each rubbish container and giving coaching and knowledge more about management hospital rubbish appropriate regulation be related to each other. Permenkes R.I no. 1204/Menkes/SK/X/2004 about rules and regulations of hospital area healthy, Government Rules R.I no. 18 th 1999 about management waste $B 3$.

Keywords : Management hospital rubbish, Technical operational preparation of rubbish, Medic and nonmedic rubbish.

\section{Pendahuluan}

Rumah Sakit Umum Daerah Ade Moehammad Djoen merupakan Rumah Sakit rujukan, izin operasional berdasarkan SK Bupati Sintang Nomor 1254 tanggal 30 Juli 2010 berlokasi di Jalan Patimura Kecamatan Sintang, Kelurahan Tanjungpuri Sintang yang berdiri di atas tanah seluas $8500 \mathrm{~m}^{2}$. Rumah Sakit ini memiliki 126 kamar tidur, dan spesialis rawat jalan, unit gawat darurat (UGD), laboraturium, radiologi, ICU, instalasi bedah, dan lain-lainnya.

Berdasarkan laporan tahunan tahun 2013, Rumah Sakit Umum Daerah (RSUD) memiliki 303 karyawan tetap dan 118 karyawan honor berupa jumlah karyawan laki-laki sebanyak 129 orang dan karyawan perempuan sebanyak 292 orang tersebar di masing-masing unit ruangan. Setiap unit ruangan memiliki tingkat aktifitas yang beragam dari kegiatan medis dan nonmedis, dari kegiatan tersebut menghasilkan sampah berupa sampah medis dan nonmedis. Diantara dua golongan sampah tersebut memiliki karakteristik dan penanganan yang tidak sama. Kegiatan medis sendiri menghasilkan sampah berupa, alat suntik, tabung infus, bungkus/botol obat, obat kadaluarsa, kaca slide, kantong darah dan lain-lain. Sedangkan dari kegiatan nonmedis menghasilkan sampah berupa, bungkus makanan, kertas, sisa sayuran, catrige film, sarung tangan, masker dan lain-lain. Terkendala pada aspek teknis operasional pengolahan sampah antara lain seperti wadah sampah, Tempat Penampungan Sementara (TPS) medis, gerobak/troli pengangkut sampah, Ketersediaan fasilitas masih kurang memadai dikhawatirkan menimbulkan permasalahan baik langsung maupun tidak langsung. Dampak langsung yang dapat dirasakan yaitu dapat mencemari udara/bau tidak sedap, menimbulkan penyakit menular, dan tentu dari segi estetika tidak begitu baik. Sedangkan dampak tidak langsung dapat menjadi berbagai macam sarang serangga yang dikhawatirkan menjadi faktor penyakit di Rumah Sakit Umum Daerah (RSUD) tersebut. Karena itu perlu dilakukan monitoring terhadap pengelolaan sampah di Rumah Sakit Umum Daerah (RSUD) Ade M. Djoen Sintang.

\section{Tinjauan Pustaka}

\section{a. Limbah Rumah Sakit}

Pengelolaan sampah medis dan nonmedis rumah sakit sangat dibutuhkan dalam kenyamanan dan kesehatan rumah sakit, karena dapat memutuskan mata rantai penularan penyakit menular. Partikel debu dalam sampah dapat menimbulkan pencemaran udara yang dapat menimbulkan penyebaran penyakit dan terkontaminasinya peralatan medis dan makanan (Ditjen PPL dan PLP, 2002). Sistem pengelolaan sampah dimulai dari penyimpanan sampah sementara, pengumpulan sampah di tempat pengumpulan sementara (TPS) sampah dan pengangkutan ke tempat pembuangan akhir (TPA) sampah untuk dimusnahkan. Pemanfaatan kembali (daur ulang) dan pengolahan kembali hingga pembuangan akhir dan pemusnahan sampah memberi kontribusi dalam pengurangan sumber. Penyebaran penyakit infeksi di rumah sakit (Ditjen PPM dan PLP, 1991). Keberhasilan sistem pengelolaan sampah berkaitan erat dengan prosedur tetap (protap) yang dimiliki rumah sakit sebagai acuan agar tujuan akhir pengelolaan sampah dapat tercapai sesuai dengan yang diinginkan. Apabila protap telah disusun dan dilaksanakan dengan baik, maka akan dapat tercipta lingkungan rumah sakit yang bersih dan sehat. Limbah Rumah Sakit menurut Permenkes R.I nomor: 1204/Menkes/SK/X/2004 tentang persyaratan kesehatan lingkungan Rumah Sakit adalah semua limbah yang dihasilkan dari kegiatan rumah sakit dalam bentuk padat, cair, dan gas. Limbah rumah sakit bisa mengandung 
bermacam-macam mikroorganisme bergantung pada jenis rumah sakit, tingkat pengolahan yang dilakukan sebelum dibuang. Limbah cair rumah sakit dapat mengandung bahan organik dan anorganik yang umumnya diukur dan parameter BOD, COD, TSS, dan lain-lain. Sementara limbah padat rumah sakit terdiri atas sampah mudah membusuk, sampah mudah terbakar, dan lain-lain. Limbah-limbah tersebut kemungkinan besar mengandung mikroorganisme patogen atau bahan kimia beracun berbahaya yang menyebabkan penyakit infeksi dan dapat tersebar ke lingkungan rumah sakit yang disebabkan oleh teknik pelayanan kesehatan yang kurang memadai, kesalahan penanganan bahan-bahan terkontaminasi dan peralatan, serta penyediaan dan pemeliharaan sarana sanitasi yang masih buruk. Limbah benda tajam adalah semua benda yang mempunyai permukaan tajam yang dapat melukai / merobek permukaan tubuh.

Pembuangan limbah yang berjumlah cukup besar ini paling baik jika dilakukan dengan memilah-milah limbah ke dalam berbagai kategori. Masing-masing jenis kategori diterapkan cara pembuangan limbah yang berbeda. Prinsip umum pembuangan limbah rumah sakit adalah sejauh mungkin menghindari risiko kontaminasi (Abednego. M, 1993). Indonesia pada umumnya menerapkan satuan volume. Penggunaan satuan volume dapat menimbulkan kesalahan dalam interpretasi karena terdapat faktor kompaksi yang harus diperhitungkan. Sebagai ilustrasi, 10 unit wadah yang berisi air masing-masing 100 liter, bila air tersebut disatukan dalam wadah yang besar, maka akan tetap berisi 1000 liter air. Namun 10 unit wadah yang berisi sampah 100 liter, bila sampah tersebut disatukan dalam sebuah wadah, maka volume sampah akan berkurang karena mengalami kompaksi. Beberapa studi memberikan angka timbulan sampah kota di Indonesia berkisar antara 2-3 liter/orang/hari dengan densitas $200-300 \mathrm{~kg} / \mathrm{m}^{3}$ dan komposisi sampah organik $70-80 \%$. Untuk memberikan gambaran tentang timbulan sampah ini. Berdasarkan hasil kajian dari WHO yang dilakukan terhadap 100 buah rumah sakit di Jawa dan Bali pada tahun 2002 menunjukkkan bahwa rata-rata produksi sampah sebesar 3,2 kg/tempat tidur/hari. Produksi sampah berupa limbah domestik sebesar $76,8 \%$ dan berupa limbah infeksius sebesar 23,2\%. Diperkirakan secara nasional produksi sampah (limbah padat rumah sakit) sebesar 376,089 ton/hari. Dari gambaran tersebut dapat dibayangkan betapa besar potensi rumah sakit untuk mencemari lingkungan (WHO, 2005).

\section{b. Pengelolaan Limbah Rumah Sakit}

Untuk memudahkan mengenal jenis limbah yang dimusnahkan, perlu dilakukan penggolongan limbah. Dalam kaitan dengan pengelolaan, limbah medis dikategorikan menjadi 5 golongan sebabagi berikut.

\section{c. Pemisahan}

Golongan A:

Dressing bedah yang kotor, swab dan limbah lain yang terkontaminasi dari ruang pengobatan hendaknya ditampung dalam bak penampungan limbah medis yang mudah dijangkau bak sampah yang dilengkapi dengan pelapis pada tempat produksi sampah. Kantong plastik tersebut hendaknya diambil paling sedikit satu hari sekali atau bila sudah mencapai tiga perempat penuh. Kemudian diikat kuat sebelum diangkut dan ditampung sementara di bak sampah klinis. Bak sampah tersebut juga hendaknya diikat dengan kuat bila mencapai tiga perempat penuh atau sebelum jadwal pengumpulan sampah. Sampah tersebut kemudian dibuang dengancara sebagai berikut.

1) Sampah dari haemodialisis

Sampah hendaknya dimasukkan dengan incinerator. Bisa juga digunakan autoclaving, tetapi kantung harus dibuka dan dibuat sedemikian rupa sehingga uap panas bisa menembus secara efektif.

(Catatan: Autoclaving adalah pemanasan dengan uap di bawah tekanan dengan tujuan sterilisasi terutama untuk limbah infeksius).

2) Limbah dari unit lain

Limbah hendaknya dimusnahkan dengan incinerator. Bila tidak mungkin bisa menggunakancara lain, misalnya dengan membuat sumur dalam yang aman. 
Semua jaringan tubuh, plasenta dan lain-lain hendaknya ditampung pada bak limbah medis atau kantong lain yang tepat kemudian dimusnahkan dengan incinerator. Perkakas laboratorium yang terinfeksi hendaknya dimusnahkan dengan incinerator. Incinerator harus dioperasikan di bawah pengawasan bagian sanitasi atau bagian laboratorium.

Golongan B:

Syringe, jarum dan cartridges hendaknya dibuang dengan keadaan tertutup. Sampah ini hendaknya ditampung dalam bak tahan benda tajam yang bilamana penuh (atau dengan interval maksimal tidak lebih dari satu minggu) hendaknya diikat dan ditampung di dalam bak sampah klinis sebelum diangkut dan dimasukkan dengan incinerator.

\section{d. Penampungan}

Sampah klinis hendaknya diangkut sesering mungkin sesuai dengan kebutuhan. Sementara menunggu pengangkutan untuk dibawa ke incinerator atau pengangkutan oleh dinas kebersihan (atau ketentuan yang ditunjuk), sampah tersebut hendaknya.

1) Disimpan dalam kontainer yang memenuhi syarat.

2) Di lokasi/tempat yang strategis, merata dengan ukuran yang disesuaikan dengan frekuensi pengumpulannya dengan kantong berkode warna yang telah ditentukan secara terpisah.

3) Diletakkan pada tempat kering/mudah dikeringkan, lantai yang tidak rembes, dan disediakan sarana pencuci.

4) Aman dari orang-orang yang tidak bertanggungjawab; dari binatang, dan bebas dari infestasi serangga dan tikus.

5) Terjangkau oleh kendaraan pengumpul sampah (bila mungkin).

Sampah yang tidak berbahaya dengan penanganan pendahuluan (jadi bisa digolongkan dalam sampan klinis), dapat ditampung bersama sampah lain sambil menunggu pengangkutan.

\section{e. Pengangkutan}

Pengangkutan dibedakan menjadi dua yaitu pengangkutan intenal dan eksternal. Pengangkutan internal berawal dari titik penampungan awal ke tempat pembuangan atau ke incinerator (pengolahan on-site). Dalam pengangkutan internal biasanya digunakan kereta dorong. Kereta atau troli yang digunakan untuk pengangkutan sampah klinis harus didesain sedemikian rupa sehingga.

1) Permukaan harus licin, rata dan tidak tembus.

2) Tidakakan menjadi sarang serangga.

3) Mudah dibersihkan dan dikeringkan.

4) Sampan tidak menempel pada alat angkut.

5) Sampan mudah diisikan, diikat, dan dituang kembali.

Bila tidak tersedia sarana setempat dan sampah klinis harus diangkut ke tempat lain.

1) Harus disediakan bak terpisah dari sampah biasa dalam alat truk pengangkut. Dan harus dilakukan upaya untuk men-cegah kontaminasi sampah lain yang dibawa.

2) Harus dapat dijamin bahwa sampah dalam keadaan aman dan tidak terjadi kebocoran atau tumpah.

\section{Metodelogi Penelitian}

Pengambilan data primer dilakukan dengancara sampling timbulan dan komposisi sampah. Sampling dilakukan dengan metode SNI 19-3964-1994 yaitu pengukuran sampah dengan sampling box selama 8 hari berturut-turut yang kemudian akan menghasilkan data volume, berat jenis dan komposisis sampah.

\section{a. Pengambilan Sampel}

Dalam proses pengukuran sampah menggunakan peralatan diantaranya. 
1. Kantong plastik sampah, digunakan untuk menampung serta memilah sampah baik itu sampah medis maupun nonmedis.

2. Timbangan, digunakan untuk mengukur berats ampah, timbangan yang digunakan yaitu timbangan manual $50 \mathrm{~kg}$.

3. Alat pengukur volume sampah, berupa bak berukuran $(50 \mathrm{~cm} \times 50 \mathrm{~cm} \times 60 \mathrm{~cm})$ digunakan untuk mengukur tinggi sampah digunakan kayu ukur.

4. Sarung tangan, penggunaaan sarung tangan bertujuan sebagai alat pelindung diri, mengikuti prosedur tetap yang berlaku di rumah sakit tersebut.

5. Masker, digunakan untuk melindungi bau yang tidak baik/busuk dari sampah tersebut, dan digunakan pada saat pengukuran dan pemilhan sampah.

6. Kayu ukur, digunakan untuk mengetahui tinggis ampah yang bertujuan untuk mengetahui volume timbulan sampah.

Pada penelitian ini pengukuran timbulan sampah dilakukan disetiap masing-masing unit ruangan. Untuk sampah nonmedis dalam satu hari dilakukan pengukuran dua kali dikarenakan dalam satu hari terdapat dua kali proses pengumpulan sampah dimulai dari jam 05.30 WIB dan 15.00 WIB. Untuk sampah medis perlakuannya sama dengan sampah nonmedis, dalam waktu satu hari dilakukan dua kali pengukuran timbulan sampah.

b. Pengukuran Sampel

c. Pengukuran Berat Sampah

Pengkuran berat sampah dilakukan dengan langakah-langkah sebagai berikut (SNI 193964-1994):

1. Menyiapkan peralatan pengukuran yaitu timbangan.

2. Memilah sampah sesuai komposisi sampah.

3. Menimbang sampah yang telah dipilah.

4. Mencatat hasil timbangan.

\section{d. Pengukuran Volume Sampah}

Pengukuran volume sampah dilakukan dengan langkah-langkah sebagai berikut (SNI 193964-1994) :

1. Menyiapkan peralatan pengukuran yaitu kayu ukur.

2. Mengukur panjang, lebar, dan tinggi kayu ukur.

3. Memilah sampah sesuai karakteristik.

4. Memasukan sampah sesuai karakteristik.

5. Memasukan sampah yang telah dipilah kedalam kotak.

6. Mengetuk kotak sebanyak tiga kali.

7. Mengukur tinggi sampah.

8. Mencatat hasil pengukuran.

\section{e. Analisa Data}

Menganalisa teknis operasional dimulai dari tahap pewadahan, pemilahan, pengumpulan, pengangkutan.

- Pewadahan, mengamati dan menganalisa fasilitas pewadahan yang tersedia di Rumah Sakit Umum Daerah tersebut bagaimana kondisi yang ada, jika kondisi wadah rusak, dan terjadi overload perlu di lakukan perhitungan perwadahan dimasing-masing unit ruangan mengikuti ketatapan ( SNI 19-3964-1994) metode pengambilan dan pengukuran contoh timbulan dan komposisi sampah perkotaan, Rumus untuk menghitung jumlah wadah sampah sebagai berikut: Jumlah wadah sampah $=\frac{\text { Volume timbulan sampah tertinggi ( Perhari ) }}{\text { Ukuran wadah sampah (120 Liter ) } 2 \text { Ritasi }}$ merokemendasikan pewadahan yang baik susai Peraturan Pemerintah Nomor 18 Tahun 1999, tentang pengelolaan limbah B3, dan Keputusan Mentri Kesehatan Republik 
Indonesia Nomor 1204/Menkes/Sk/X/2004 tentang persyaratan kesehatan lingkungan rumah sakit.

- Pemilahan, mengamati dan menganalisa proses pemilahan, baik itu sampah medis maupun nonmedis. Apakah masih ada sampah yang tercampur pada proses pemilahan, dan membandingkan apakah sudah sesuai dengan Permenkes R.I, Nomor 1204/Menkes/SK/IV/2004 tentang Persyaratan Kesehatan Lingkungan Rumah Sakit, jika belum sesuai akan diberikan rekomendasi dalam penangganannya.

- Pengumpulan, mengamati dan menganalisa proses pengumpulan padawadah di masingmasing unit ruang dan membandingkan apakah sudah sesuai dengan Permenkes R.I, Nomor 1204/Menkes/SK/IV/2004 tentang Persyaratan Kesehatan Lingkungan Rumah Sakit, jika belum sesuai akan diberikan rekomendasi dalam penangganannya.

- Pengangkutan, Mengamati dan menganalisa proses pengangkutan sampah medis dan nonmedis dari awal pengangkutan sampai selesai dan membandingkan apakah sudah sesuai dengan Permenkes R.I, Nomor 1204/Menkes/SK/IV/2004 tentang Persyaratan Kesehatan Lingkungan Rumah Sakit, jika belum sesuai akan diberikan rekomendasi dalam penangganannya.

\section{Hasil dan Pembahasan}

\section{a. Hasil Pengamatan Berat dan Volume Sampah}

\begin{tabular}{|c|l|c|c|c|c|}
\hline \multirow{2}{*}{ No } & \multirow{3}{*}{ Unit Ruangan } & \multicolumn{2}{|c|}{$\begin{array}{c}\text { Rata-rata Sampah medis } \\
\text { / hari }\end{array}$} & \multicolumn{2}{c|}{$\begin{array}{c}\text { Rata-rata Sampah } \\
\text { nonmedis / hari }\end{array}$} \\
\cline { 3 - 6 } & & berat / kg & volume $\mathrm{m}^{3}$ & berat / kg & $\begin{array}{c}\text { volume } \\
\mathrm{m}^{3}\end{array}$ \\
\hline 1 & IGD & 10,20 & 0,46 & 16,06 & 0,60 \\
\hline 2 & Penyakit dalam & 13,83 & 0,62 & 22,10 & 0,80 \\
\hline 3 & Dapur & 0,00 & 0,00 & 5,65 & 0,21 \\
\hline 4 & Bedah & 5,88 & 0,26 & 9,58 & 0,36 \\
\hline 5 & Bersalin & 4,70 & 0,21 & 9,31 & 0,35 \\
\hline 6 & ICU & 5,00 & 0,22 & 7,96 & 0,27 \\
\hline 7 & Laboratorium & 1,75 & 0,07 & 1,98 & 0,08 \\
\hline 8 & Mayat & 1,19 & 0,05 & 1,84 & 0,07 \\
\hline 9 & Rontgen & 1,41 & 0,06 & 1,50 & 0,06 \\
\hline 10 & VIP & 4,68 & 0,21 & 7,60 & 0,25 \\
\hline \multicolumn{2}{|c|}{ Total Rata-rata } & 4,63 & 2,16 & $8, .58$ & 3,06 \\
\hline
\end{tabular}

Rata-rata/hari sampah padat di RSUD Ade Moehammad Djoen pada sepuluh titik sumber timbulan didapatkan angka yang beragam, dan itu merupakan jumlah rata-rata/hari timbulan sampah selama delapan hari pengamatan yang dilakukan pada masing-masing unit ruang, sampah medis tertinggi terdapat pada unit ruang penyakit dalam dan anak dengan nilai rata-rata sebesar $13,83 \mathrm{~kg} /$ hari $\left(0,62 \mathrm{~m}^{3}\right)$, untuk sampah nonmedis tertinggi terdapat pada unit ruang penyakit dalam dan anak dengan nilai rata-rata sebesar $22,10 \mathrm{~kg} / \mathrm{hari}\left(0,80 \mathrm{~m}^{3}\right)$. Total ratarata produksi sampah medis secara keseluruhan mencapai 48,63 $\mathrm{kg} / \mathrm{hari}\left(2,16 \mathrm{~m}^{3}\right)$, dan untuk sampah nonmedis secara keseluruhan mencapai $83,58 \mathrm{~kg} /$ hari $\left(3,06 \mathrm{~m}^{3}\right)$. 


\section{b. Eksisting dan Rekomendasi wadah Sampah}

\begin{tabular}{|c|c|c|c|c|c|c|c|c|c|c|}
\hline \multirow[t]{2}{*}{ No } & \multirow[t]{2}{*}{ Unit } & \multicolumn{2}{|c|}{$\begin{array}{c}\text { Eksisting Wadah Yang } \\
\text { Tersedia }\end{array}$} & \multicolumn{2}{|c|}{$\begin{array}{l}\text { Eksisting Perhitungan } \\
\text { Penambahan Wadah }\end{array}$} & \multicolumn{2}{|c|}{$\begin{array}{l}\text { Total Wadah ( Wadah } \\
\text { Tersedia + Perhitungan } \\
\text { Penambahan Wadah }\end{array}$} & \multicolumn{2}{|c|}{$\begin{array}{c}\text { Perhitungan Wadah/Bed ( } 2.5 \\
\mathrm{Kg} / \text { Bed atau } 0.16 \mathrm{~m}^{3} \text { ) Berdasarkan } \\
\text { Standar WHO }\end{array}$} & \multirow[t]{2}{*}{$\begin{array}{l}\text { Kapasitas Wadah Yang } \\
\text { Digunakan }\end{array}$} \\
\hline & & Medis & Nonmedis & Medis & Nonmedis & Medis & Nonmedis & Medis & Nonmedis & \\
\hline 1 & IGD & 5 & 5 & 3 & 3 & 8 & 8 & 13 & 13 & 60 Liter \\
\hline 2 & Penyakit Dalam dan Anak & 4 & 4 & 4 & 4 & 8 & 8 & 88 & 88 & 60 Liter \\
\hline 3 & Dapur & 1 & 1 & 1 & 1 & 2 & 2 & 0 & 0 & 60 Liter \\
\hline 4 & Bedah & 5 & 5 & 0 & 0 & 5 & 5 & 39 & 39 & 60 Liter \\
\hline 5 & Bersalin & 2 & 2 & 2 & 2 & 4 & 4 & 23 & 23 & 60 Liter \\
\hline 6 & ICU & 2 & 2 & 2 & 2 & 4 & 4 & 7 & 7 & 60 Liter \\
\hline 7 & Laboraturium & 1 & 1 & 0 & 0 & 1 & 1 & 0 & 0 & 60 Liter \\
\hline 8 & Mayat & 1 & 1 & 0 & 0 & 1 & 1 & 0 & 0 & 60 Liter \\
\hline 9 & Rontgen & 2 & 2 & 0 & 0 & 2 & 2 & 3 & 3 & 60 Liter \\
\hline 10 & VIP & 2 & 2 & 1 & 1 & 3 & 3 & 7 & 7 & 60 Liter \\
\hline & Total Wadah & 25 & 25 & 13 & 13 & 38 & 38 & 179 & 179 & \\
\hline
\end{tabular}

ketersediaan wadah yang ada sebanyak 25 wadah sampah medis dan 25 wadah sampah nonmedis, total wadah sebanyak 50 wadah sampah. Dengan kondisi demikian perlu dilakukan penambahan wadah sampah dikarenakan wadah yang tersedia masih belum cukup untuk menampung sampah yang dihasilkan dari aktifitas kesehariannya di rumah sakit tersebut. Penambahan wadah sesuai perhitungan selama pengamatan berlangsung dengan kondisi tempat tidur pasien tidak penuh diperlukan sebanyak 24 wadah sampah medis dan 24 wadah sampah nonmedis. Sehingga total wadah sampah yang diperlukan sesuai perhitungan sebanyak 49 wadah sampah medis dan 49 wadah sampah nonmedis yang tersebar pada masing-masing ruangan. Jika dibandingkan dengan standar WHO, rata-rata rumah sakit menghasilkan sampah sebanyak 3,2 $\mathrm{Kg} / \mathrm{Bed} / \mathrm{Hari}$. Dengan menggunakan kapasitas wadah medis dan nonmedis sebesar 60 liter, rumah sakit Ade M. Djoen Memerlukan wadah sampah sebanyak 176 wadah sampah medis dan 176 wadah sampah nonmedis dalam kondisi tempat tidur pasien terisi penuh.

\section{c. Rekomendasi}

\section{Pewadahan}

Penambahan wadah menyesuaikan kapasitas wadah yang tersedia dan tidak mengganti wadah secara keseluruhan dikarenakan wadah yang tersedia masih layak digunakan. Dari sepuluh unit ruangan terdapat 4 ruangan yang tidak direkomdasikan penambahan pawadah yaitu ruang bedah, laboratorium, mayat dan rontgen, karena selama pengamatan berlangsung ketersediaan wadah pada ruang tersebut masih dapat menampung sampah dan tidak terjadi overload sampah pada kedua ruangan tersebut.

Selain itu kondisi wadah yang tidak memiliki tutup disarankan dilakukan penambahan tutup pada masing-masing wadah tersebut. Sampah nonmedis dibuang pada TPS pasar inpres, sedangkan sampah medis di tampung pada TPS RSUD Ade Moehammad Djoen, kondisi fisik bangunan TPS komunal sampah medis sangat tidak layak, direkomendasikan diperbaiki dan dibuat dengan menggunakan bahan yang solid, kedap air, dan memiliki tutup, agar tidak mencemari lingkungan sekitar rumah sakit. Ketentuan pewadahan sesuai karakteristik sampah telah di atur dalam Peraturan Menteri Kesehatan R.I Nomor 1204/Menkes/SK/X/2004 tentang Persyaratan Kesehatan Lingkungan Rumah Sakit dan Peraturan Pemerintah RI. Nomor 18 Tahun 1999, Tentang Pengelolaan Sampah B3.

\section{Pemilahan dan Pengumpulan}

Pada proses pemilahan masih tercampur baik itu sampah medis dan nonmedis dan ketersediaan label atau penamaan pewadahan perlu diperhatikan agar mencegah tercampurnya antara sampah medis dan nonmedis. Ketersediaan kantong wadah harus sesuai dengan jenis/karaktersitik sampah kuning untuk sampah medis dan hitam untuk nonmedis. 
Pada proses pemilahan direkomendasikan menggunakan APD (Alat pelindung diri), seperti masker, handscoon, sepatu, dan sebelum dan sesudah kegiatan berlangsung menggunakan alkohol untuk membersihkan tangan dan setelahnya mencuci tangan untuk mencegah terserang penyakit dan bakteri. Dengan kondisi kantong pelastik ditemukan masih ada yang bocor dan cairan dari sampah tersebut tercecer pada permukaan lantai, direkomendasikan diberihkan dengan menggunakan larutan klorin susai Permenkes R.I Nomor 1204/Menkes/SK/X/2004, menjelaskan tentang penangganan pemilahan dan pengangkutan sampah.

Pengumpulan dilakukan langsung oleh petugas sanitasi / CS, pengumpulan langsung pada sumber timbulan sampah, pada proses pemilahan, pengumpulan, pengagkutan petugas belum menggunkan sepatu / boot dan hanya menggunakan alas kaki berupa sandal direkomendasikan selama proses berlangsung menggunkan APD untuk mencegah terjadinya kecelakaan selama proses berlangsung.

\section{Pengangkutan}

Proses pengangkutan selama ini menggunkan satu troli untuk sampah nonmedis, sedangkan untuk sampah medis di angkut manual karena tidak ada troli pengangkut khusus sampah medis. Ketersediaan troli yang ada sudah mulai rusak dan berlubang pada bagian alas maupun dinding troli, ukuran yaitu $1,5 \mathrm{~m}^{3}$, dengan kondisi demikian direkomdasikan masingmasing troli untuk masing-masing jenis sampah medis maupun nonmedis sebagai berikut.

\begin{tabular}{|c|c|c|c|c|c|}
\hline \multirow{2}{*}{ No } & \multicolumn{2}{|c|}{$\begin{array}{c}\text { Jumlah Troli Pengangkut } \\
\text { Sampah/Hari }\end{array}$} & \multicolumn{2}{|c|}{ Ukuran Troli $\left(\mathrm{m}^{3}\right)$} & \multirow{2}{*}{ Keterangan } \\
\cline { 2 - 5 } & Medis & Nonmedis & Medis & Nonmedis & \\
\hline 1 & 1 & 1 & $1,5 \mathrm{~m}^{3}$ & $1,5 \mathrm{~m}^{3}$ & $\begin{array}{c}\text { Masing-masing 1 } \\
\text { Troli untuk sampah } \\
\text { padat medis dan } \\
\text { nonmedis }\end{array}$ \\
\hline
\end{tabular}

Masing-masing jenis sampah baik itu Medis dan nonmedis direkomendasikan masingmasing satu troli pengangkut dengan kapasitas $1,5 \mathrm{~m}^{3}$, Ukuran troli pengangkut sampah menyesuaikan ukuran troli sebelumnya, selain itu juga menyesuaikan kondisi rute jalan yang di lalui pada bangunan rumah sakit. Rekomendasi troli disaranakan menggunakan bahan yang solid, kedap air, dan memiliki penutup berdasarkan Permenkes Nomor 1204/Menkes/Sk/X/2004 tentang persyaratan kesehatan rumah sakit. Dipilih troli yang tertutup karena jalur pengangkutan sampah medis dan nonmedis menggunakan jalur umum atau jalur yang sama dengan karyawan lainnya.

\section{Kesimpulan dan Saran}

\section{a. Kesimpulan}

1. Secara khusus belum memiliki protap dalam penanganan sampah medis maupun nonmedis termasuk di dalamnya yaitu aspek teknis operasional pengelolaan sampah medis dan nonmedis yang secara umum memiliki perlakuan yang berbeda dalam penanganannya.

2. Rekomendasi yang dianjurkan yaitu dengan menambah wadah sesuai perhitungan eksisting masing-masing sebanyak 13 wadah medis dan 13 wadah nonmedis sesuai ketentuan Permenkes R.I Nomor.1204/Menkes/SK/X/2004, tentang persyaratan kesehatan lingkungan rumah sakit, serta memberikan label/penamaan pada masingmasing wadah sampah dan menambahkan beberapa fasilitas penunjang pengelolaan sampah diantaranya troli sampah mesid, TPS (tempat penampungan sementara) sampah 
medis, dan kelengapan $\mathrm{k} 3$ sesuai prosedur pelaksanaan bagi petugas kebersihan di rumah sakit

\section{b. Saran}

1. RSUD Ade M. Djoen Sintang perlu melakukan peninjauan, pemantauan, serta evaluasi terhadap pelaksanaan dan kinerja petugas dalam pengelolaan persampahan di rumah sakit.

2. Perlu membuat protap khusus penangganan sampah padat medis dan nonmedis serta memberi pelatihan dan pengetahuan langsung kepada petugas kebersihan yang menanggani proses pengelolaan persampahan di lingkungan rumah sakit.

3. Perlu menambah fasilitas penunjang pengelolaan sampah seperti wadah sampah, troli pengangkut sampah, dan tempat penampungan sementara ( TPS ) sampah padat medis, dan kelengkapan APD untuk petugas kebersihan.

\section{Ucapan Terima Kasih}

Dengan selesainya penelitian ini saya mengucapkan terima kasih yang sebesar-besarnya kepada Allah swt, kedua orang tua, kedua dosen pembimbing yaitu, Dian Rahayu Jati,S.T,M.Si, Isna Apriani, S.T, M.Si , serta kepada teman-teman Fakultas Teknik Angkatan 2008 dan semua orang yang telah berperan dalam membantu penelitian yang tidak dapat disebutkan satu persatu. Harapan saya penelitian ini bermanfaat dan dapat dipergunakan sebagaimana mestinya.

\section{Daftar Pustaka}

Abednego m. 1993. Pengelolaan Limbah Rumah Sakit. Makalah Seminar Limbah Rumah Sakit.

Bestari a. 2007. Pengelolaan limbah rumah sakit bontang. Semarang: Skripsi Program Magister Ilmu Lingkungan Universitas Diponegoro.

Cunningham. 2004. Tahap pengelolaan sampah modern.

Departemen Kesehatan Republik Indonesia Tahun 2009 Tentang Jenis Limbah Rumah Sakit.

Ditjen PPM dan PLP. 1991. Pedoman Pengelolaan Limbah Klinis .Jakarta: Departemen Kesehatan RI.

Ditjen PPM dan PLP. 2002. Pedoman Sanitasi Rumah Sakit di Indonesia. Jakarta: Departemen Kesehatan RI.

Dirjen PPM dan PLP Departemen Kesehatan RI No. HK.00.06.44.93 tentang Syarat Kesehatan Lingkungan Rumah Sakit.

Laporan Tahunan RSUD Ade M. Djoen Kota Sintang Kabupaten Sintang 2013. Profil RSUD Ade M Djoen Sintang.

Notoadmodjo.2003. Pendidikan dan Perilaku Kesehatan. Jakarta: PT. Rineka Cipta.

Peraturan Menteri Kesehatan RI No.340/Menkes/Per/III/2010 tentang Klasifikasi Lingkungan Rumah Sakit.

Peraturan Menteri Kesehatan RI No.1204/Menkes/SK/X/2004 tentang Persyaratan Kesehatan Lingkungan Rumah Sakit.

Peraturan Pemerintah RI. No.18 Tahun 1999, Tentang Pengelolaan Sampah B3.

Pujiati 2004. Upaya Peningkatan Pengelolaan Limbah Padat Berdasarkan Hasil Evaluasi Penerapan Protap : Studi Kasus Pengelolaan Limbah Padat Rumah Sakit Dr. Iskak Kabupaten Tulungagung). Thesis. Surabaya: Program Pascasarjana Universitas Airlangga.

SNI 19-3964-1994. Metode Pengambilan dan Pengukuran Contoh Timbulan dan Komposisi Sampah Perkotaan. 
SNI 19-2454-2002. Teknis Operasional Pengelolaan Sampah Perkotaan.

SNI 19-3983-1995. Spesifikasi Timbulan Sampah Untuk Kota Kecil dan Kota Sedang di Indonesia. SNI 19-7030-2002. Tentang Tata-tata Cara Teknik Operasional Pengelolaan Sampah Perkotaan. SNI 3242-2008. Tentang Pengelolaan Sampah di Permukiman.

Sugiyono, DR. 2003. Statistika Untuk Penelitian. Bandung : CV Alvabeta.

Undang-Undang Nomor 18 tahun 2008 Tentang Pengelolaan Sampah.

WHO, 2005, Pengelolaan Aman Limbah Layanan Kesehatan, Jakarta. 